\title{
Ischemia Impairs the Association Between Connexin 43 and M3 Subtype of Acetylcholine Muscarinic Receptor (M3-mAChR) in Ventricular Myocytes
}

\author{
Peng Yue ${ }^{1}$, Yong Zhang ${ }^{1}$, Zhimin $\mathrm{Du}^{1}$, Jing Xiao ${ }^{1}$, Zhenwei Pan ${ }^{1}$, \\ Ning Wang ${ }^{1}$, Haiyan $\mathrm{Yu}^{1}$, Wencai Ma ${ }^{1}$, Hong Qin ${ }^{1}$, Wen-Hui Wang ${ }^{2}$, \\ Dao-Hong Lin ${ }^{1,2}$ and Baofeng Yang ${ }^{1}$
}

'Department of Pharmacology, Harbin Medical University, Bio-Pharmaceutical Key Laboratory of Heilongjiang Province, Harbin, ${ }^{2}$ Department of Pharmacology, New York Medical College, Valhalla

\section{Key Words}

Gap junction channel • Muscarinic receptor • Choline - Ischemia • Receptor trafficking

\begin{abstract}
We used Western blot analysis to examine the expression of connexin 43 and M2/M3 acetylcholine muscarinic receptors (mAChR) and their interaction in ventricular myocytes from control and the ischemic heart. We confirmed that the connexin 43 and M2/ M3-mAChR were expressed in ventricular myocytes. Moreover, we showed that M3-mAChR was expressed in non-glycosylated $(72 \mathrm{kDa})$ and glycosylated forms $(115 \mathrm{kDa})$. Immunostaining showed that connexin 43 is closely associated with M3-mAChR in parts of cell membranes of myocytes. Immunoprecipitation of lysate of cardiac myocytes with M2/M3-mAChR antibody pulled down a $44 \mathrm{kDa}$ protein recognized by connexin 43 antibody. Ischemia increased the expression of M3-mAChR in myocytes. The ischemiainduced increase in the M3-mAChR expression was specific because ischemia did not affect the expression of M1, M2, M4 and M5- mAChR in the heart. On the other hand, ischemia decreased the expression of connexin 43 in myocardium. We also examined the effect of ischemia on the interaction
\end{abstract}

\section{KARGER}

Fax +41613061234

E-Mail karger@karger.ch

www.karger.com
(C) 2006 S. Karger AG, Basel

$1015-8987 / 06 / 0174-0129 \$ 23.50 / 0$

Accessible online at:

www.karger.com/journals/net between M2/M3-mAChR and connexin 43. Ischemia suppressed the association of M3-mAChR with connexin 43 but did not affect the association of connexin 43 with M2-mAChR. Administration of choline before ischemia not only partially restored the expression of connexin 43 but also attenuated the ischemia-induced suppression of the association between connexin 43 and M3-mAChR. We conclude that connexin 43 interacts with M2/M3-mAChR and that ischemia specifically impairs the association between M3-mAChR and connexin 43.

Copyright (C) 2006 S. Karger AG, Basel

\section{Introduction}

A large body of evidence indicates that multiple subtypes of muscarinic acetylcholine receptors are expressed in myocardium [1-5]. A new member of the $\mathrm{mAChR}$ family is M3-mAChR which has been shown to be expressed in atrium and ventricle [2-4, 6, 7]. M3AChR is a G-protein coupled receptor and plays an important role in the regulation of a variety of cell functions in tissue other than heart. For instance, M3-mAChR has been shown to have anti-apoptotic effects and its Cterminus is responsible for the anti-apoptotic properties

Dr. Dao-Hong Lin, Dept Pharmacol, New York Med College,

Valhalla, NY 10595 (USA), Tel. +1 914594 4139, Fax +1914 3474956 or Baofeng Yang, Ph.D, Dept Pharmacol, Harbin Med University,

Heilongjiang 150086 (China), Tel. +8645186669473, Fax +8645186669482

E-Mail yangbf@ems.harmu.edu.cn 
[8]. Although the role of M3-mAChR in the regulation of myocyte function is largely unknown, available evidence suggests that M3-mAChR may be involved in the regulation of ion channels. Stimulation of M3-mAChR has been demonstrated to increase G-protein-coupled K channels [7], presumably mediated by activation of delayed rectifier $\mathrm{K}$ channels. As consequence of activation of M3-mAChR-coupled K currents, the cardiac action potential duration was decreased in myocytes. Therefore, it is possible that $\mathrm{M} 3-\mathrm{mAChR}$ is involved in the modulation of excitability or action potential of myocytes.

In addition to ion channels, gap-junction channels also play a role in facilitating prolongation of action potential by providing a low-resistance pathway for the electrical signal. Connexin43 is the most abundant gap junction channel in a variety of tissues including heart and kidney $[7,9,10]$. Because gap-junction channels play an important role in cell-cell communication [11], a progressive remodeling of gap junction takes place in response to a variety of stimulation. It has been well established that the number of gap-junction channels in the cell membrane is regulated by hormones/ neurotransmitters [12, 13], receptors $[9,14,15]$ and factors such as ATP-depletion induced by ischemia [10]. It has been reported that inhibition of angiotensin II receptor increases the expression of connexin 37 and 40 and decreases the expression of connexin 43 in vascular endothelial cells [15]. Moreover, hormones can affect the function of the gap-junction channels not only through changing protein translation but also by modulating the function of the gap-junction through the interaction or close association of receptors with gap-junction channels. It has been shown that purinergic receptor $\mathrm{P} 2 \mathrm{X} 1$ is closely associated with connexin 43 in human ventricular myocardium [9]. Thus, the goal of the present study was to examine whether M3-mAChR can interact with connexin 43 and whether this interaction would be affected by ischemia.

\section{Materials and Methods}

\section{Animal preparation and cell culture}

We used male Wistar rats (280-300g) in the experiments and animals were divided into control and ischemic groups. The rats were anesthetized with sodium pentobarbital $(45 \mathrm{mg}$ / $\mathrm{kg}$ ) and the respiration of rats was controlled by a small ventilator. The animal temperature was maintained by placing them on a heating pad. The method to create an ischemic model has been described previously [16] and we followed the same protocol. After the experiments, the animals were sacrificed
Fig. 1. A Western blot showing the expression of M3-mAChR (top panel) and connexin 43 (bottom panel) in the right ventricle.

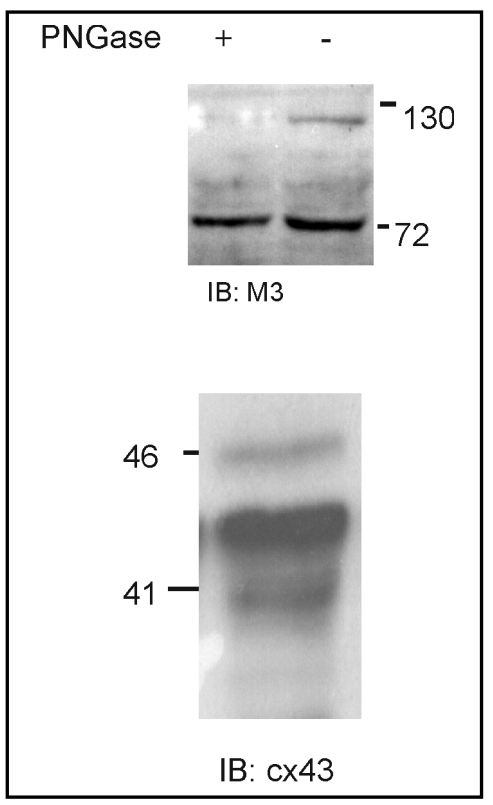

and the right ventricle, which had no ischemia-induced tissue damage, was immediately removed and prepared for either immunocytochemistry or Western blot. For isolation of single myocytes, the heart was cut into small pieces and incubated with collagenase $(0.1 \%)$-containing solution. Freshly isolated myocytes were placed onto 96 -well plates and grown at $37^{\circ} \mathrm{C}$ in DMEMF12 medium containing $10 \%$ FBS in $\mathrm{CO}_{2}$ incubator for 6 hr.

\section{Membrane protein preparation}

The right ventricle was removed and rinsed in PBS buffer ( $\mathrm{pH7.4)}$ three times. The sample was transferred to a turtle bottle and mixed with $0.5 \mathrm{ml}$ PBS buffer solution containing protease inhibitors, smashed and centrifuged at $500 \mathrm{~g}$ for $5 \mathrm{~min}$. After removing the pellet, the protein sample was ultracentrifuged at $35,000 \mathrm{~g}$ for $30 \mathrm{~min}$ and resuspended with 100ul $0.4 \%$ SDS Ripa Buffer. The protein concentrations were determined using protein assay kit by spectrophotometer (Eppendorf).

\section{Immunoprecipitation and immunoblot}

$200 \mu \mathrm{g}$ membrane proteins were used for each IP experiment and mixed with $3 \mu \mathrm{g}$ corresponding antibody in $1 \mathrm{ml}$ PBS. The tube containing the mixture was placed on a rotator and incubated at $4 \mathrm{C}^{\circ}$ overnight. We then added $25 \mu$ Protein A agarose to the tube containing the sample and it was further incubated at room temperature for an additional $1 \mathrm{hr}$ followed by centrifuging for $1 \mathrm{~min}$ at $2000 \mathrm{~g}$. The samples were washed twice with PBS (pH7.2) and the pellet was resuspended in $2 \mathrm{X}$ sample buffer. The sample was boiled for $3 \mathrm{~min}$ followed by centrifuge. We used $10 \%$ SDS-PAGE denatured protein gel to separate the protein sample and the protein was transferred to PVDF membrane by a semi-dry transfer. The membrane was then exposed to the corresponding antibody for $1 \mathrm{hr}$ followed by three washings in $0.02 \%$ TBST for $10 \mathrm{~min}$ each. We used ECL plus to detect bands and the intensity of the band was determined by densitometry.

Yue/Zhang/Du/Xiao/Pan/Wang/Yu/Ma/Qin/Wang/Lin/Yang 
Fig. 2. A confocal image showing the expression of connexin 43 in myocardium under control conditions (A) and after ischemia (B).

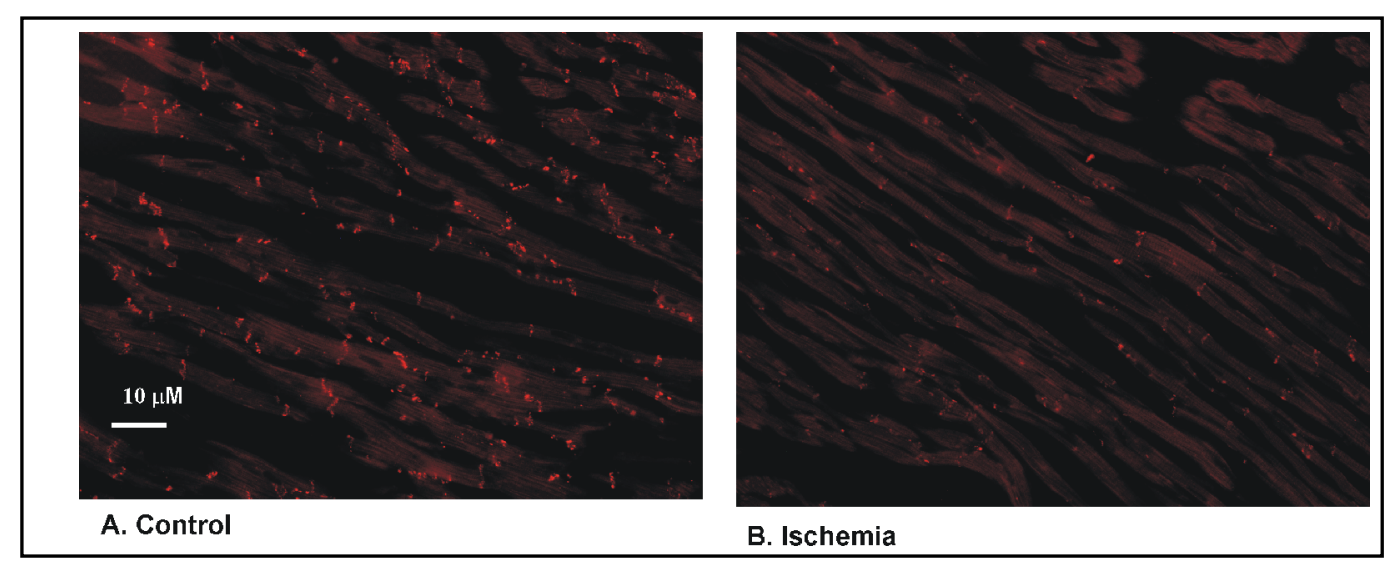

Fig. 3. A confocal image showing the expression of connexin 43 (red) and M3$\mathrm{mAChR}$ in a i s o 1 a t e d myocyte.
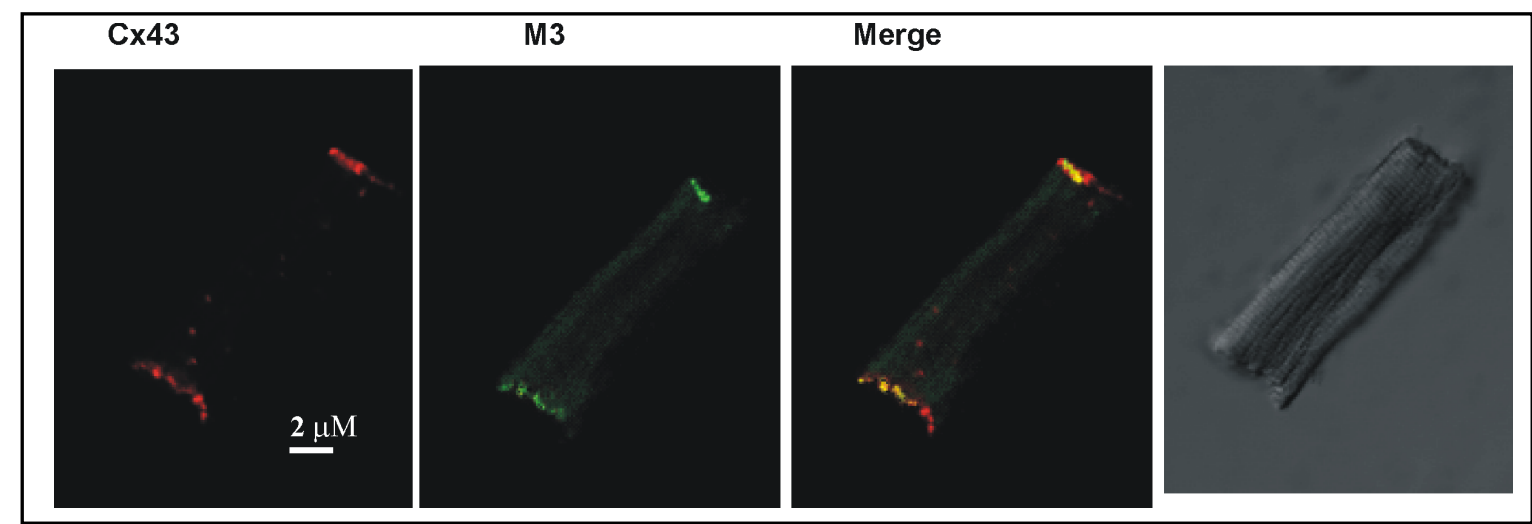

\section{Confocal microscope}

Connexin 43 and M3-mAChR in myocytes were detected by confocal microscopy. Briefly, AlexFlour594 and AlexFlour 488 dyes were excited at $594 \mathrm{nM}$ and $488 \mathrm{nM}$, respectively and viewed with an inverted Olympus FV300 confocal system equipped with a X40 lens. All images were acquired and processed with identical parameters.

\section{Statistics and reagents}

Mono-clone anti-connexin 43 antibody, antibodies for M1, 2, 4 and $5 \mathrm{mAChR}$, protein A agarose, goat anti-mouse Ig, goat anti-rabbit Ig were from SantaCruz. Anti-M3-mAChR was from Alomone Biolab (Israel). AlexFlour594 conjugated goat antimouse Ig and AlexFlour488 conjugated goat anti-rabbit Ig were from molecular probes. Data are presented as mean \pm SEM. We used Student t' test to compare the significance between the control and experimental group. We considered the difference as significant if $\mathrm{p}$ values were less than 0.05 .

\section{Results}

We first used Western blot to examine the expression of connexin 43 and M3-mAChR in right ventricles. Fig. 1 is a typical Western blot showing that M3-mAChR (top panel) and connexin 43 (lower panel) are expressed in the myocytes. Western blot with M3-mAChR antibody

M3-mAChR and Connexin 43 detected two bands of proteins: a $115 \mathrm{kDa}$ and a $72 \mathrm{kDa}$, from rat heart. The $72 \mathrm{kDa}$ protein corresponds to the predicted molecular size from amino acid sequence whereas a $115 \mathrm{kDa}$ protein band is consistent with the size reported by other investigators [5]. To test whether the $115 \mathrm{kDa}$ band represents a glycosylated M3-mAChR, we treated the protein with PNGase to remove the sugar. From inspection of Fig. 1, it is apparent that treatment of the protein with PNGase eliminated the $115 \mathrm{kDa}$ band. This suggests that M3-mAChR can be expressed in both deglycosylated and glycosylated forms. Western blot also detected three bands of connexin 43, 46, 44 and $41 \mathrm{kDa}$ (Fig.1). It is well established that the top two bands are phosphorylated connexin 43 whereas the $41 \mathrm{kDa}$ band represents unphosphorylated gap-junction channels. It is apparent that the $44 \mathrm{kDa}$ band (phosphorylated) is a major type of connexin 43 expressed in plasma membrane under control conditions. We also examined the expression of connexin 43 in myocytes under the control conditions. From inspection of Fig.2A is apparent that connexin 43 is mainly expressed in the intercalated disc.

After confirming the presence of M3-mAChR and connexin 43, we examined the localization of the two proteins in the isolated myocytes. Fig. 3 is a typical confocal image showing the location of M3-mAChR and 
Fig. 4. A Western blot showing that connexin 43 is coimmunoprecipitated with M2/M3-mAChR antibody (top). The middle and low panels demonstrate the M2 and M3-mAChR, respectively. The samples were immunoprecipitated with polyclone anti-M2 and M3-mAChR or rabbit $\mathrm{IgG}$ (negative control) and separated by electrophoresis. The connexin 43 was detected with monoclone antibody whereas M2 and M3mAChR were detected with goat polyclone antibodies.

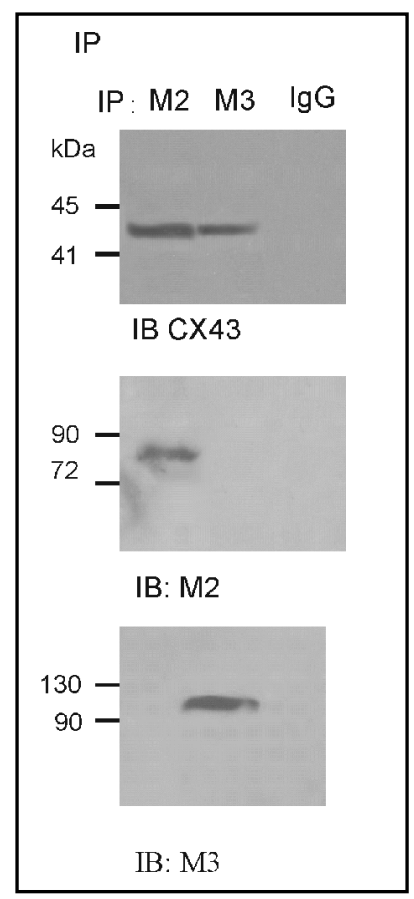

connexin 43 in the myocyte. It is clear that connexin 43 is mainly expressed in intercalated discs. We confirmed the previous finding that $\mathrm{M} 3-\mathrm{mAChR}$ is not evenly distributed in the cell plasma membrane but is heavily distributed in the intercalated disc. However, there is a clear overlap between M3-mAChR and connexin 43. To test the possibility that M3-mAChR may be directly or closely associated with connexin 43, we carried out immunoprecipitation experiments with $\mathrm{M} 3$ or M2-mAChR antibody to pull-down proteins which interact with M3 or M2-mAChR. The proteins were resolved with electrophoresis and exposed to connexin antibody. Fig. 4 is a typical recording from five such experiments showing that connexin 43 is detected from the protein immunoprecipitated with M3 or M2-mAChR antibody. We calculated that the fraction of the total connexin 43 pool which interacts with M2 and M3-mAChR was $23 \%$ and $20 \%$, respectively. Thus, connexin 43 is closely interacted with M3 and M2-mAChR with similar affinity. Interestingly, when the same membrane was stripped and exposed to M3-mAChR antibody, the main band reacted with M3-mAChR was $115 \mathrm{kDa}$ protein. This suggests that the glycosylated M3-mAChR is able to interact with connexin 43.

After establishing that M3 or M2-mAChR is closely associated with connexin 43 , we examined whether the interaction between connexin 43 and mAChR is affected by ischemia. We followed the protocol described previously to create an ischemic model, and tissue samples

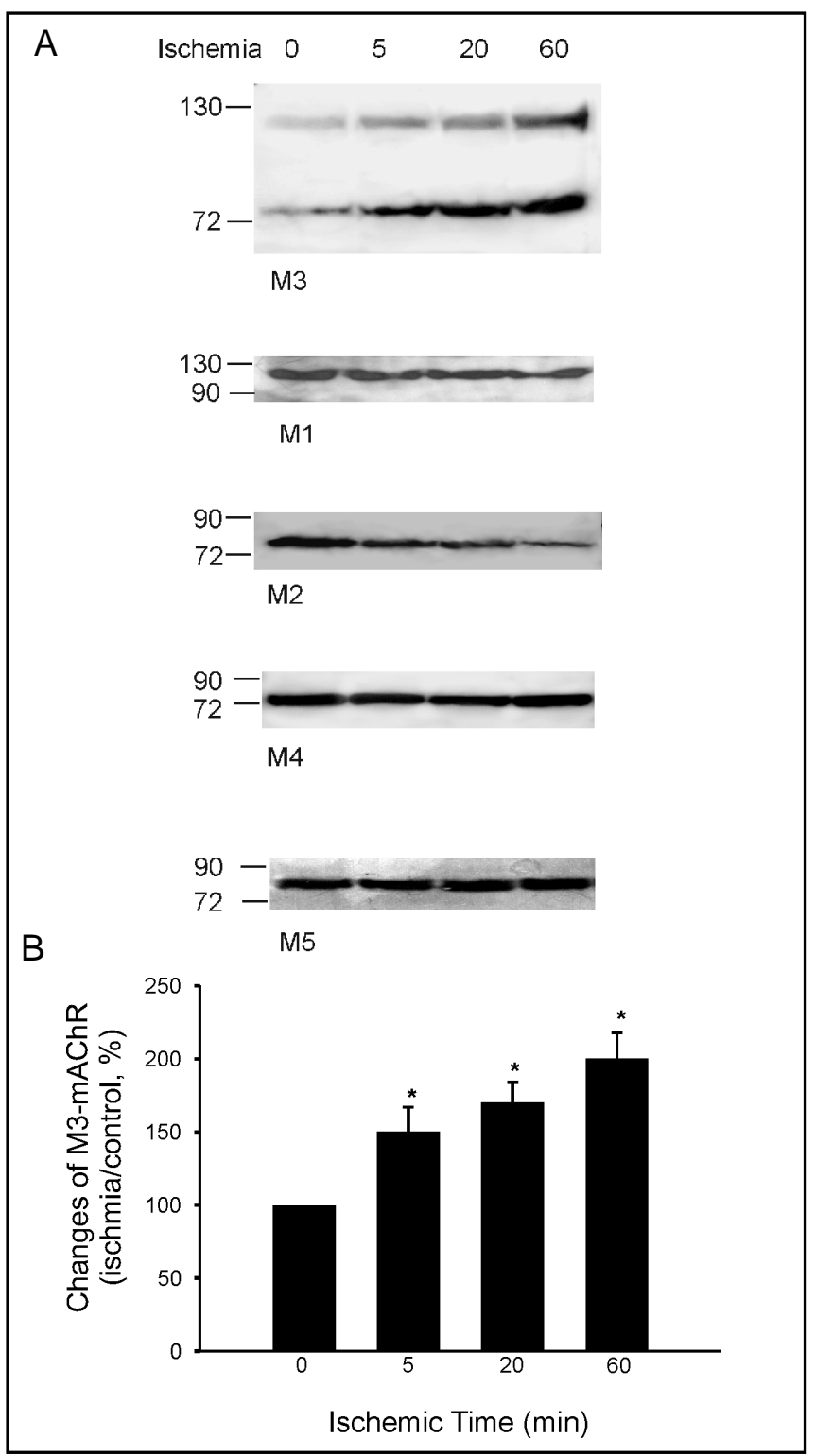

Fig. 5. (A) A Western blot demonstrating the effects of ischemia on the expression of M1, M2, M3, M4 and M5-mAChR in the heart. (B) A bar graph summarizes the data from 5 such experiments showing that ischemia increased the expression of M3-mAChR in the plasma membrane. The data were a mean value of both $72 \mathrm{kDa}$ and $115 \mathrm{kDa}$ bands. Asterisk indicates that the difference is significant from the control value $(\mathrm{P}<0.05)$.

were taken from the right ventricle of the heart exposed to 5, 20 and $60 \mathrm{~min}$ ischemia. We first examined the effect of ischemia on the expression of M1 to M5-mAChR in the cell plasma membrane. Fig. 5 is a representative Western blot demonstrating the effect of ischemia on M1 to M5-mAChR expression. From inspection of Fig.5, it is clear that ischemia did not have an effect on the expression of M1, M2, M4 and M5-mAChR in the plasma

Yue/Zhang/Du/Xiao/Pan/Wang/Yu/Ma/Qin/Wang/Lin/Yang 


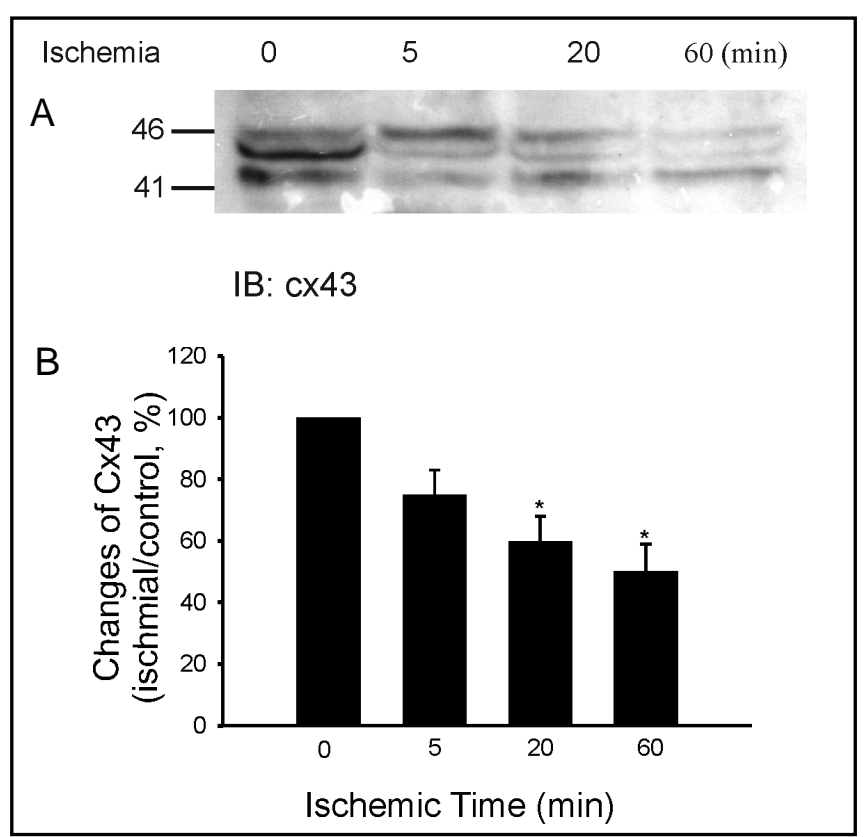

Fig. 6. The top panel (A) is a Western blot showing the effect of ischemia on the expression of connexin 43 in the plasma membrane. The bottom panel (B) is a bar graph summarizing the experiments in which the effect of ischemia on connexin 43 were examined. The changes represent a mean value of three bands in comparison to the control value.

membrane. In contrast, the membrane expression of M3$\mathrm{mAChR}$ increased sharply in response to ischemic stimulation. Moreover, it is apparent that ischemia increased both $72 \mathrm{kDa}$ and $115 \mathrm{kDa}$ (glycosylated) M3$\mathrm{mAChR}$ in myocytes. We also examined the effect of ischemia on the expression of connexin 43 in plasma membrane (Fig. 6). In contrast to M3-mAChR which increased in the plasma membrane after ischemic stimulation, the expression of connexin 43 decreased in the plasma membrane progressively in response to ischemia. Ischemia-induced decrease in connexin 43 expression in cell membranes was also confirmed by fluorescence microscopy (Fig. 2B). In contrast to the control image in which connexin 43 was clearly located in the intercalated discs and cell plasma membranes, 60 min ischemia diminished the density of the connexin 43 in myocytes.

Since decreases in the connexin 43 expression in the plasma membrane occurred as early as 5 min after ischemia, it is unlikely that the decrease was the result of a down-regulation of protein synthesis. We speculate that the ischemia-induced decreases in connexin 43 expression in plasma membrane resulted from, in part, an enhanced internalization or decreased delivery. Because M2/M3-

M3-mAChR and Connexin 43

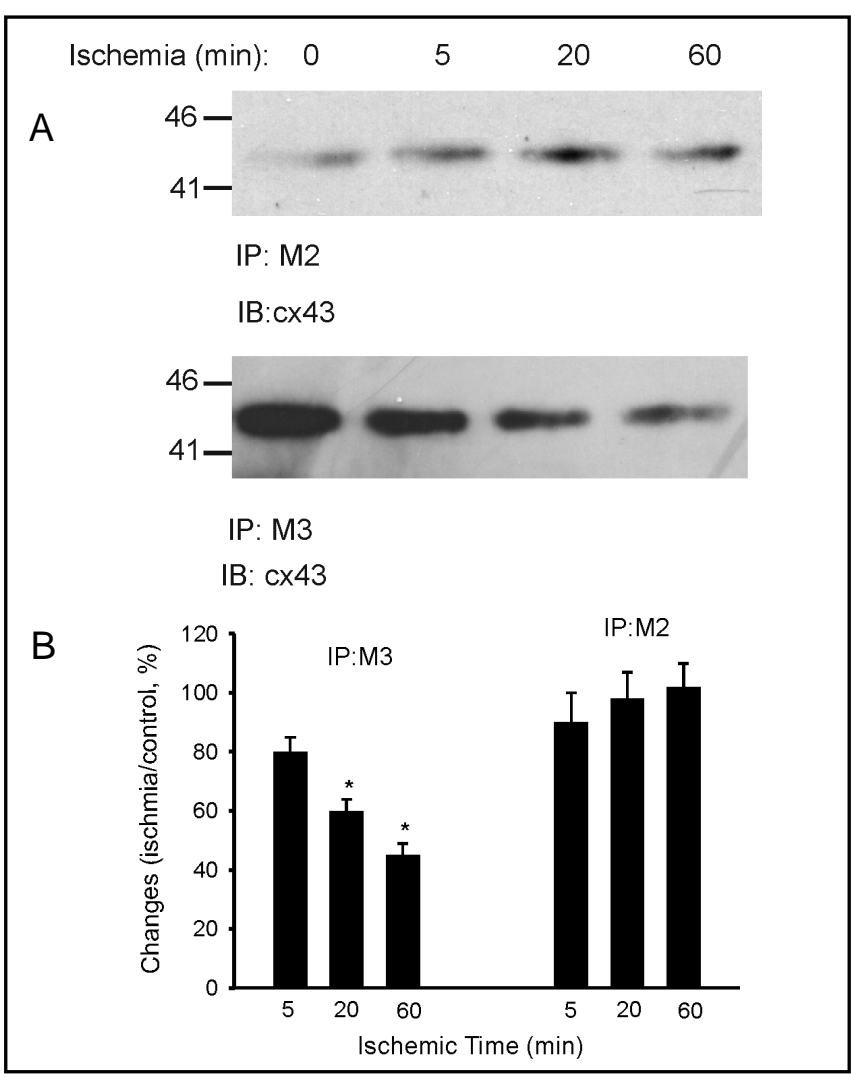

Fig. 7. (A) A Western blot showing the effect of ischemia on the association between M2 or M3-mAChR and connexin 43 . (B) Data from at least 5 such experiments are summarized. Asterisk indicates that data were significantly different from the control value $(\mathrm{P}<0.05)$.

mAChR are closely associated with connexin 43 , it is possible that ischemia could alter the association of M2/ M3-mAChR with connexin 43. Thus, we next examined whether ischemia has an effect on the interaction between connexin 43 and M2/M3-mAChR. We harvested the membrane fraction of proteins of myocytes from rat heart exposed to ischemia for 5-60 min. The protein samples were immunoprecipitated with either M2 or M3-mAChR antibody and separated by electrophoresis. Fig. 7 is a typical Western blot showing the effect of ischemia on the association of connexin 43 with M2/M3-mAChR. It is clear that ischemia did not significantly affect the association between M2-mAChR and connexin 43 but significantly suppressed the association between M3$\mathrm{mAChR}$ and connexin 43. Although it is possible that decrease in the co-immunoprecipitation between M3mAChR and connexin 43 induced by ischemia may be partially the result of reduced pool of total connexin 43 . However, this can not be completely attributed to decreased expression of connexin 43 because the M3- 
Fig. 8. (A) A Western blot showing the effect of choline pretreatment on the association between M3/M2 mAChR and connexin 43. (B) A bar graph summarizes the data from 5 such experiments in which the effect of choline on the association between M3 or M2 mAChR and connexin 43 was examined. (C) A Western blot demonstrating the effect of choline on the expression of connexin 43 in response to ischemia.

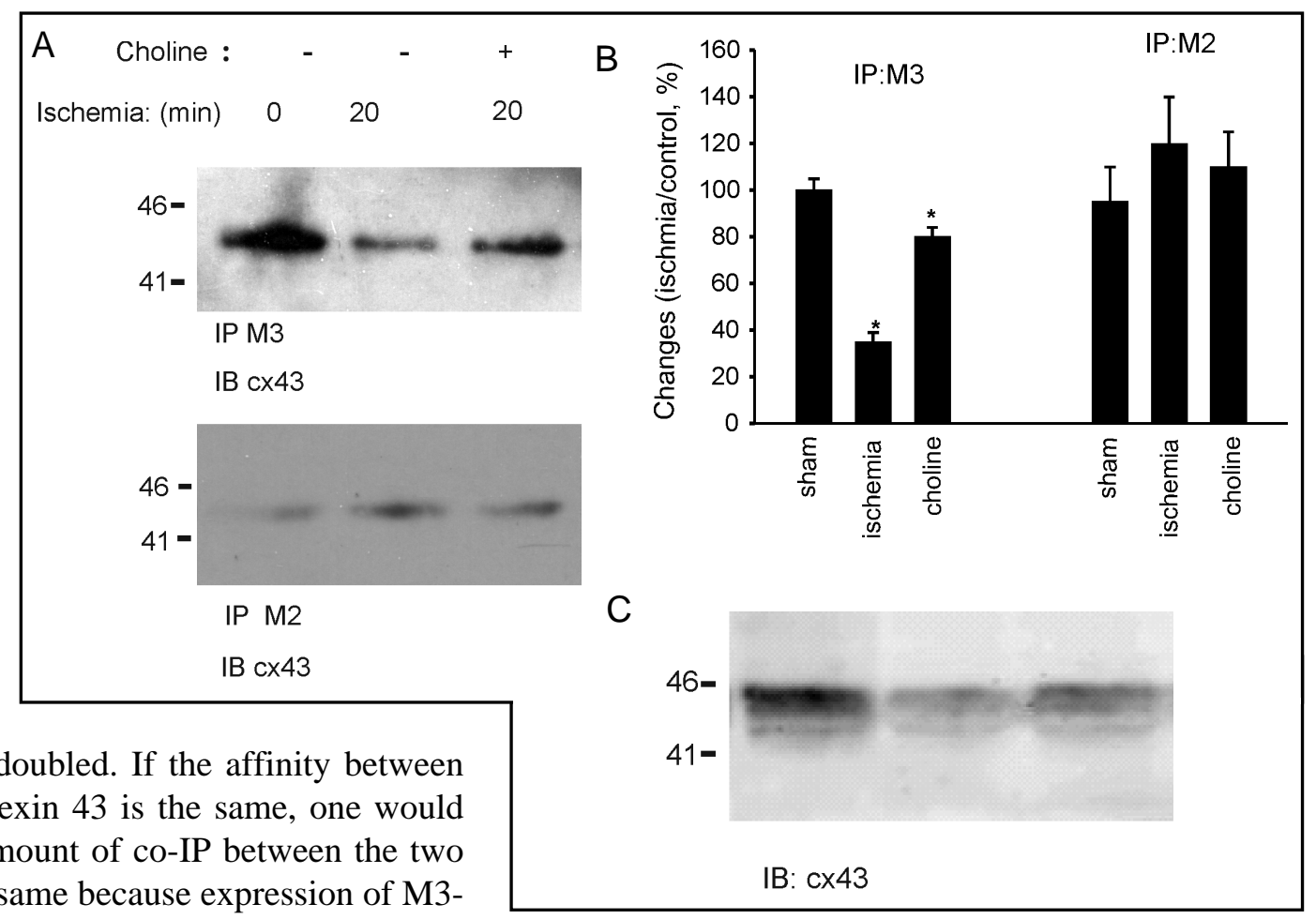

down connexin 43 ; 2) confocal microscopy showed that connexin 43 and M3-mAChR were colocalized in some parts of the cell membrane. It is now well accepted that receptors and ion channels and their regulators are closely associated to form a functional unit [17]. This interaction can be achieved by lipid raft, scaffolding proteins or direct binding. Indeed, it has been shown that ZO-1, a PDZdomain protein, increased association with connexin 43 during remodeling of cardiac gap junction [18]. Thus, it is possible that the PDZ-domain containing proteins may be involved in mediating the association between M3mAChR and connexin 43. We need further experiments to explore the mechanism by which connexin 43 interacts with M3-AChR.

It is well established that connexin 43 can directly interact with different receptors and ion transporters [9, $19,20]$. A relevant example is the finding that $\mathrm{P} 2 \mathrm{X} 1$ receptor is closely associated with connexin 43 in myocardium [9]. Similar to our observation that connexin 43 and M3-mAChR are colocalized only in some parts of the cell membranes, colocalization of connexin 43 and P2X1 receptors was also observed only in some parts of cell membranes. The partial colocalization betweem mAChR and gap-junctions could be the result of gapjunction remodeling through association and dissociation with M3-mAChR.

The function of such physical closeness between M3-mAChR and gap junction channels is not clear. It is

Yue/Zhang/Du/Xiao/Pan/Wang/Yu/Ma/Qin/Wang/Lin/Yang 
possible that this association could facilitate the spatiotemporal coordination of function of M3-mAChR and connexin 43. It has been shown that coexpression of connexin 43 and $\mathrm{P} 2 \mathrm{Y}$ purinergic receptors in astrocytes synchronized the cell gap junction communication with $\mathrm{Ca} 2+$ signaling induced by stimulation of the $\mathrm{P} 2 \mathrm{Y}$ receptor [21]. It is well documented that hormones or neurotransmitters can modulate the function of gap junction channels by at least three mechanisms: 1) through protein transcription and translation. Relevant to this is the report that thyroid hormone stimulates the receptors binding to the promoter region of connexin 43 and increases the connexin $43 \mathrm{mRNA}$ in liver [13]. In osteocytes, stimulation of EP2 receptors by prostaglandins increased the expression of connexin 43 and gap junction function [14]. Application of endothelin-1 and angiotensin II augmented the expression of connexin 40 and 43 in the heart [22] and the effect of endothelin and angiotensin II was mediated by mitogen-activated protein kinases. 2) through the modulation of gap-junction channel trafficking. It has been reported that adrenocorticotropin (ACTH) increased the size and number of connexin 43 on the cell membrane in adrenal cells by stimulation of gap junction transport from vesicles to the cell membrane [12]. 3) through regulation by direct interaction between gapjunction channels and receptors or ion transporters [9, $19,20]$. It has been reported that purinergic receptors are closely associated with connexin 43 and that the colocalization between connexin 43 and purinergic receptors may be important for the function of myocardium because it coordinates the effects between connexin 43 and purinergic receptor $\mathrm{P} 2 \mathrm{Y}$ to achieve a fast propagation of intracellular $\mathrm{Ca} 2+$ signals [21].

M3-mAChR has been shown to regulate delayedrectifying $\mathrm{K}$ channels [7]. Thus, it is conceivable that M3mAChR should play an important role in the cell repolarization which can indirectly affect $\mathrm{Ca}^{2+}$ influx through voltage-gated $\mathrm{Ca} 2+$ channels. Since gap-junction channels are important for the cell-cell communication, it is likely that a close association between connexin 43 and M3-AChR may play a role in coordinating the rate of repolarization of cardiomyocytes. Ischemia impairs such interaction between gap-junction channels and M3$\mathrm{mAChR}$ and, accordingly, it could interrupt the cell-cell communication and the propagation of action potential. Thus, it is possible that ischemia-induced cardiac arrhythmia could be partially induced by uncoupling between M3-mAChR and connexin 43. This speculation is also supported by the finding that choline treatment, which has been shown to protect the heart from ischemia-

M3-mAChR and Connexin 43 induced damage [16], attenuated the ischemia-induced suppression of the association between M3-AChR and connexin 43 . The mechanism by which choline pretreatment attenuates the ischemia induced suppression of the association between M3-mAChR and the gapjunction is not clear. It may be related to stimulation of the muscarinic receptors. Several studies have demonstrated that stimulation of muscarinic receptors improves functional recovery of the heart after ischemia $[23,24]$. Therefore, it is conceivable that M3-mAChR could be a target for protecting the heart from ischemiainduced injury.

In the present experiments, we observed that ischemia decreased the expression of connexin 43 but increased the expression of M3-mAChR. This alteration in connexin 43 and M3-mAChR expression was unlikely the result of changing the rate protein synthesis because we observed the ischemia-induced decreases in connexin 43 expression in as short as $5 \mathrm{~min}$. We speculate that changes in connexin 43 and M3-mAChR expression were most likely the result of altered connexin 43 and M3$\mathrm{mAChR}$ trafficking. Ischemia could either enhance the internalization or inhibit the insertion of connexin 43 and have an opposite effect on M3-AChR.

The finding that ischemia suppressed the association between M3-mAChR and connexin 43 could not be the result of a decreased expression of connexin 43 because the association of connexin 43 with M2-mAChR was not affected by ischemia. Thus, our data strongly suggest that ischemia specifically affects the association between M3-mAChR and connexin 43. However, the mechanism by which ischemia affects the interaction between M3$\mathrm{mAChR}$ and connexin 43 is not understood. Ischemia has been shown to cause defective coupling between the muscarinic receptor and Gq-proteins in hippocampus [25]. Also, it is well known that anoxia can stimulate mitogenactivated protein kinase (MAPK) such as ERK, P38 and JNK [26, 27]. ERK has been shown to mediate the effect of EGF on gap-junction channels, decreasing gap-junction channels [28]. Stimulation of MAPK could lead to activate c-Src which is known to regulate the membrane protein trafficking. We have shown that stimulation of MAPK could increase the internalization of ROMK channels by a c-Src-dependent pathway [29]. However, further experiments are needed to explore the role of MAPK in mediating the effect of ischemia on the coupling between connexin 43 and M3-mAChR. We conclude that connexin 43 is closely associated with M2/M3-mAChR in the rat heart and that ischemia specifically impairs the association between M3-mAChR and gap-junctions. 


\section{References}

Wang ZG, Shi H, Wang HZ: Functional $>_{11}$ M3 muscarinic acetycholine receptors in mammalian hearts. Br J Pharmacol 2004; 142:395-408.

2 KreJci A, Tucek S: Quantitation of mRNAs for M1 to M5 subtypes of muacarinic receptors in rat heart and brain cortex. Mol Pharmacol $\triangleright_{13}$ 2002;61:1267-1272.

3 Dobrev D, Knuschke D, Richter F, Wettwer E, Christ T, Knaut M, Ravens $\mathrm{U}$ : Functional identification of $\mathrm{m} 1$ and m3 muscarinic acetylcholine receptors in human atrial myocytes: influence of chronic atrial fibrillation. Circulation 2002;19:111-154.

4 Ponicke K, Heinroth-Hoffmann I, Brodde OE: Demonstration of functional M3 muscarinic receptors in ventricular cardiomyocytes of adalt rats. $\mathrm{Br} \mathrm{J}$ Pharmacol 2003;138:156-160.

-5 Wang HZ, Han H, Zhang LM, Shi H, Schram G, Nattel S, Wang ZG: Expression of multiple subtypes of muacarinic receptors and cellular distribution in the human heart. Mol Pharmacol 2001;59:1029-1036.

-6 Shi H, Wang H, Lu Y, Yang B, Wang ZG: Choline modulates cardiac membrane repolarization by activating an M3 muscarinic receptor and its coupled $\mathrm{K}$ channel. J Membr Biol 1999;169:55-64. Shi H, Wang HZ, Yang BF, Xu DH, Wang ZG: The M3 receptor mediated $\mathrm{K}$ current ( $\mathrm{I}_{\mathrm{KM} 3}$ ) a Gq protein-coupled $\mathrm{K}$ channel. J $>18$ Biol Chem 2004;279:21774-21778. Budd DC, McDonald J, Emsley N, Cain $\mathrm{K}$, Tobin $\mathrm{AB}$ : The C-terminal tail of the M3-muscarinic receptor possesses antiapoptotic properties. J Biol Chem $>19$ 2003;278:19565-19573.

$>9$ Jiang L, Bardini M, Keogh A, dosRemedios CG, Burnstock G: P2X1 receptors are closely associated with connexin 43 in human ventricular myocardium. Int J Cardiol 2005;98:291297.

10 Vergara L, Bao X, Cooper M, Bello-Reuss E, Reuss L: Gap junctional hemichannels are activated by ATP depletion in human renal proximal tubule cells. J Membr Biol 2003;196:173-184.
Kumar NM, Gilula NB: The gap junction $>21$ communication channel. Cell 1996;84:381-388.

12 Murray SA, Nickel BM, Gay VL: Endocytosis of connexin protein in adrenal cells. Endocr Res 2004;30:647654.

3 Stock A, Sies H: Thyroid hormone receptors bind to an element in the connexin 43 promoter. Biol Chem 2000;381:973-979.

14 Cherian PP, Cheng B, Gut S, Sprague E, $>23$ Bonewald LF, Jiang JX: Effects of mechanical strain on the function of gap junctions in osteocytes are mediated through the prostaglandin EP2 receptor. J Biol Chem 2003;278:43146-43156.

15 Kansui Y, Fujii K, Nakamura K, Goto K, 24 Oniki H, Abe I, Shibata Y, Lida M: Angiotensin II receptor blockade corrects altered expression of gap junction in vascular endothelial cells from hypertensive rats. Am J Physiol 2004;287:H216-H224.

16 Yang B, Lin HX, Xu CQ, Liu Y, Wang HZ, Han H, Wang ZG: Choline produces cytoprotective effects against ischemic myocardial injuries:Evidence for the role of cardiac M3 subtype mascarinic acetylcholin receptors. Cell Physiol Biochem 2005;16:00.

17 Dev KK: making protein interactions druggable:targeting PDZ domains. Nat Rev Drug Discov 2004;3:1047-1056. Barker RJ, Price RL, Courdie RG: Increased association of ZO-1 with connexin 43 during remodeling of cardiac gap junctions. Circ Res 2002;90:317324.

9 Malhotra JD, Thyagarajan V, Chen C, Isom LL: Tyrosine-phosphorylated and nonphosphorylated sodium channel beta1 subunits are differentially localized in cardiac myocytes. J Biol Chem 2004;279:40748-40754.

20 Petrecca K, Atanasiu R, Grinstein S, Orlowski J, Shrier A: Subcellular localization of the $\mathrm{Na} / \mathrm{H}$ exchanger NHE1 in rat myocardium. Am J Physiol $>29$ 1999;276:H709-H717.
Suadicani SO, Flores CE, UrbanMaldonado M, Beelitz M, Scemes E: Gap junction channels coordinate the propagation of intercellular $\mathrm{Ca}^{2+}$ signals generated by $\mathrm{P} 2 \mathrm{Y}$ receptor activation. Glia 2004;48:217-229.

-22 Polntchouk L, Ebelt B, Jackels M, Dhein S: Chronic effects of endothelin 1 and angiotensin II on gap junctions and intercellular communication in cardic cells. FASEB J 2002;16:87-89.

Yamaguchi F, Nasa Y, Yabe K, Ohba S, Hashizume Y, Ohaka H, Furuhama K, Takeo S: Activation of cardiac muscarinic receptor and ischemic preconditioning effects in in situ rat heart. Heart Vessels 1997; 12:74-83.

Hendrikx M, Toshima Y, Mubagwa K, Flameng W: Muscarinic receptor stimulation by carbachol improves functional recovery in isolated, blood perfused rabbit heart. Cardiovasc Res 1993;27:980-999.

-25 Takagi N, Miyake-Takagi K, Takagi K, Tamura H, Takeo S: Altered extracellular signal-regulated kinase signal transduction by the muscarinic acetycholine and metabotropic glutamate receptors after ischemia. J Biol Chem 2002;277:6382-6390.

26 Park KM, Chen A, Bonventre JV: Prevention of kidney ischemia/ reperfusion-induced functional injury and JNK,P38 and MAPK kinase activation by remote ischemic pretreatment. J Biol Chem 2001;276:11870-11876.

Cowan KJ, Storey KB: Mitogenactivated protein kinases:new signaling pathways functioning in cellular response to environmental stress. J Exp Biol 2003;206:1107-1115.

Abdelmohsen K, von Nontfort C, Stuhlmann D, Gerber PA, Decking UK, Sies H, Klotz LO: Dexorubicin induces EGF receptor-dependent downregulation of gap junction intracellular communication in rat liver epithelial cells. J Biol Chem 2005;386:217-223. Babilonia E, Wei Y, Sterling H, Kaminski P, Wolin MS: Superoxide anions are involved in mediating the effect of low $\mathrm{K}$ intake on $\mathrm{c}-\mathrm{Src}$ expression and renal $\mathrm{K}$ secretion in the cortical collecting duct. J Biol Chem 2005;280:10790-10796. 